\title{
Effectiveness of pneumatically powered penetrating and non-penetrating captive bolts in stunning cattle
}

\author{
Steffan Edward Octávio Oliveiraa ${ }^{\mathrm{a}, \mathrm{b}, *}$, Neville George Gregory ${ }^{\mathrm{c}}$, Filipe Antonio Dalla Costa ${ }^{\mathrm{a}, \mathrm{b}}$, \\ Troy John Gibson ${ }^{\mathrm{c}}$, Osmar Antonio Dalla Costa ${ }^{\mathrm{d}}$, Mateus José Rodrigues Paranhos da Costa ${ }^{\mathrm{a}, \mathrm{b}}$ \\ a Programa de Pós-graduação em Zootecnia, Faculdade de Ciências Agrárias e Veterinárias, Universidade Estadual Paulista, Jaboticabal, SP 14.884-900, Brazil \\ ${ }^{\mathrm{b}}$ Grupo de Estudos e Pesquisas em Etologia e Ecologia Animal, Departamento de Zootecnia, Faculdade de Ciências Agrárias e Veterinárias, Universidade Estadual Paulista, \\ Jaboticabal, SP 14.884-900, Brazil \\ ${ }^{\mathrm{c}}$ Royal Veterinary College, University of London, United Kingdom \\ ¿ EMBRAPA Swine and Poultry, BR 153, Km 110, Concórdia 89700-991, Brazil
}

A R T I C L E I N F O

\section{Keywords:}

Bolt velocity

Cattle slaughter

Rhythmic respiration

Signs of consciousness

\begin{abstract}
A B S T R A C T
This study assessed the effectiveness of penetrating (PCB; 190 psi; $\mathrm{N}=363$ ) and non-penetrating captive bolt guns (NPCB; 210-220 psi; $\mathrm{N}=92$ ) to stun a total of 455 cattle (Zebu and Zebu Cross). Physical bolt parameters (momentum, kinetic energy and energy density) were evaluated. Clinical indicators of brain function were recorded after stunning (GR), after being hoisted (HO) and at the bleeding rail (BL). Physical bolt parameters (bolt velocity, momentum, kinetic energy, energy density and sectional density) were significantly higher $(P<0.001)$ for PCB. The need for two or more shots was more frequent for NPCB (210-220 psi; $29 \%$ vs. $12 \%$, $P<0.001)$. Cattle were more likely to collapse at first shot with PCB (190 psi; 99\%) compared to NPCB (91\%; $P<0.002)$ which can be attributed to the higher values of bolt physical parameters. Incidence of eyeball rotation ( $5 \%$ vs. $1 \%)$ and righting behaviour $(7 \%$ vs. $1 \%)$ were higher $(P<0.001)$ for NPCB $(210-220 p s i)$ at GR than PCB. The NPCB with 210-220 psi had a higher frequency of response to nostril stimulation (2\% vs. 0\%; $P<0.001$ ) than PCB. Rhythmic respiration was more frequently found for NPCB with 210-220 psi at GR, HO and BL. Therefore, PCB with 190 psi was more effective in ensuring unconsciousness in cattle.
\end{abstract}

\section{Introduction}

Captive bolt is the most common method for stunning cattle in abattoirs (Finnie, Blumbergs, Manavis, Summersides, \& Davies, 2000). Concussion is achieved with either penetrating (PCB) or non-penetrating captive bolt guns (NPCB) (Blackmore \& Delaney, 1988). The basic principles behind their operation are the same for both methods and involve the transference of kinetic energy from the moving bolt to the brain (Farouk, 2013). However, there are differences regarding the mechanisms underlying the way these methods induce loss of consciousness.

Non-penetrating stunning imparts fast acceleration forces to the head after the impact of the large bolt with the skull. Acceleration/ deceleration forces impart large-momentum, rotational, and shear forces to the head and brain at relatively low kinetic energy (Ommaya, Goldsmith, \& Thibault, 2002). In quadrupeds, the long axes of the brain and spinal cord are parallel. This almost linear neuraxis may reduce rotational shearing after non-penetrating stunning and render the animal much less vulnerable to concussion compared with bipeds (Finnie, 2001). Besides that, the brain of many animals is better protected than that of humans by well-developed temporal muscles, and more extensive frontal sinuses. The hollow, domed, bony calvaria is resistant to considerable force, which diffuses over its surface and to the base of the skull (Summers, Cummings, \& de Lahunta, 1995). Additionally, if the head is immobilized, the injury transmitted to the brain is much less than when the head is free (Crooks, 1991).

By contrast, with penetrating stunning that are mainly designed to produce a deleterious shockwave within, and direct damage to the brain tissue, the movement of the head is reduced (Finnie et al., 2000), due to the smaller area of the head impacted by the bolt, resulting in delivery of high focal kinetic energy and relatively low cranial momentum (Ommaya et al., 2002). The intention is to induce not only a deep but also an irreversible form of concussion (Gregory, Lee, \& Widdicombe, 2007).

The most frequently used stunners for cattle in large beef abattoirs are either pneumatically powered penetrating (PCB) or non-penetrating

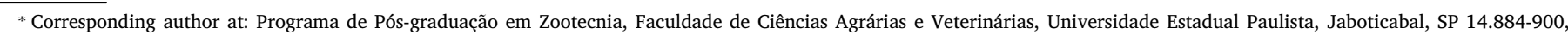
Brazil.

E-mail address: steffan_edward@yahoo.com.br (S.E.O. Oliveira).
} 
(NPCB) or captive bolt guns (EFSA, 2013). The air pressure in the gun's expansion chamber before shooting will affect the velocity of the bolt, the amount of kinetic energy delivered to the animal's head and, consequently, the effectiveness of stunning (Oliveira, Gregory, Dalla Costa, Gibson, \& Paranhos da Costa, 2017). The objective of this study was to compare the effectiveness of PCB and NPCB stunning of cattle using pneumatically powered captive bolt guns operated with high proper air line pressures.

\section{Materials and methods}

This project was approved by the Committee of Ethical Use of Animals at UNESP-FCAV, Jaboticabal-SP, Brazil (Protocol number: 022754/14).

\subsection{Abattoirs description}

The study was carried out during routine stunning and slaughter at two beef abattoirs belonging to the same company. Combined, both abattoirs slaughtered approximately 1300 animals/day, mainly bulls (over $550 \mathrm{~kg}$ liveweight) and old cows (over $400 \mathrm{~kg}$ liveweight). The animals were individually restrained in a stunning pen equipped with a head yoke (Back Hauser ${ }^{\circledast}$, Brazil), and then stunned by a slaughterman with a pneumatically powered penetrating (PCB) or non-penetrating captive bolt gun (NPCB). After the animal had rolled out of the stunning pen, it was shackled and then hoisted onto a bleeding rail, where a third slaughterman stuck it by inserting a knife into the thoracic cavity. According to the user's manual provided by the manufacturer, the operating air line pressure of the guns used at both abattoirs should be within a range of 160-190 psi for the PCB (USSS-1, Jarvis Products Corporation $^{\circledR}$ ) and 190-245 psi for the NPCB (USSS-2A, Jarvis Products Corporation $^{\circledast}$ ).

\subsection{Animals and equipment}

A total of 455 Zebu (pure, $\mathrm{N}=176$ ) and crossbred (Zebu and European cattle; $N=279$ ) bulls, castrated males, and cows (over $400 \mathrm{~kg}$ liveweight) of approximately 20 months were assigned to either one of two stunning treatments: PCB $(\mathrm{N}=363)$ and NPCB $(\mathrm{N}=92)$. Air pressure levels that powered the pneumatic guns during the evaluation were: 190 psi for PCB and within the range of 210-220 psi for NPCB. The control and verification of the desired air line pressure was done through the pressurization system and manometers of each abattoir. This was assessed by the same operator every 5 shots. The bolt diameter and length of the PCB and NPCB were 15.9 and $34.9 \mathrm{~mm}$, and 280 and $220 \mathrm{~mm}$, respectively. The bolt weight was 0.30 and $0.83 \mathrm{~kg}$ for PCB and NPCB, respectively. The bolt retrieving mechanism of both guns works through the air line pressure and is automatically activated right after the shot where it pushed back into position by the return of air pressure. The lengths of the bolt that comes out of the muzzle are 210 and $150 \mathrm{~mm}$ for PBC and NPCB, respectively, when guns were fired.

\subsection{Shooting accuracy}

Shot accuracy was assessed at the bleeding line (BL) by placing a grid printed on transparent plastic onto the head of the shot cattle and measuring the deviation between the shot hole or the mark of the nonpenetrating shot on the head and the ideal shooting position, defined by Gregory et al. (2007) as the intersection point between imaginary lines drawn between the base of each horn and the temporal corner of the contralateral eye. Deviations up to $2 \mathrm{~cm}$ from the ideal position were considered as acceptable. Shot orientation (based on compass points: $\mathrm{N}$, $\mathrm{S}, \mathrm{E}, \mathrm{W}$ ) from the ideal position was identified with the use of the same grid.

\subsection{Assessment of clinical signs of brain function}

The state of consciousness and response to pain in stunned cattle were assessed by recording clinical signs at three different stages of the production line: with the animal on the ground, just after it had rolled out of the stunning pen (GR; 1), just after being hoisted (HO; 2), and at the beginning of the bleeding rail (BL; 3). A person, standing on the platform of the stunning pen, recorded the general information about the animals (breed and gender), whether they collapsed or not after the first shot (since cattle were held with a head yoke, it was said the animal collapsed if it lost its standing posture) and the time interval between stunning and sticking. Another person recorded the state of consciousness and reflex responses at GR and $\mathrm{HO}$, and a third person did so at BL.

Except for blood extravasation from the bolt hole in the skull which was assessed by visual observation at the GR, and the assessment of the physical signs of consciousness (rhythmic respiration, corneal reflex, palpebral reflex, full eyeball rotation, response to nostril stimulation [pinching with the thumb and forefinger nails], tremor, righting behaviour, tongue protrusion, masseter relaxation, blood extravasation from the nose or mouth, tonic and clonic convulsions) was carried out according to Oliveira et al. (2017). Clonic convulsions following the shot were assessed with a $0-3$ point kicking score, where 0 represented no kicking, 1 mild, 2 vigorous kicking but not sufficient to delay shackling and sticking, and 3 was violent kicking activity which endangered staff (Gregory et al., 2007).

\subsection{Bolt velocity measurements and determination of physical parameters}

The measurements of velocity of the captive bolt when it was fired in air and the calculation of its physical parameters (momentum, kinetic energy and energy density) were performed as described by Oliveira et al. (2017). Velocity was recorded as the bolt transected seven infrared beams from LEDs placed $4 \mathrm{~mm}$ apart. The velocity meter software (2009 CBG Tester ${ }^{\circledR}$, Royal Veterinary College) was used to save the recorded data for further analysis of the bolt velocity profile. The sectional density of the bolt, which is an important parameter influencing tissue penetration and corresponds to the ratio of the bolt's mass to its cross-sectional area (calculated as the weight of the bolt, in pounds divided by the square of the bolt's diameter, in fractions of an inch), was calculated. Before shooting the air line pressure was set to 190 psi for PCB $(\mathrm{N}=21)$ and 220 psi for NPCB $(\mathrm{N}=10)$.

\subsection{Statistical analysis}

Data were analyzed by two-tailed Fisher Exact test with Graphpad software (2015 Graphpad Software, Inc) to verify the effect of stunning treatments on the clinical signals of brain function. For the analyses of bolt velocity measurements, a univariate analysis of variance was performed considering only the device used (penetrating vs. non-penetrating captive bolt guns), and using shots as sampling units. Multiple comparisons of the values of bolt velocities were performed using the Tukey-Kramer test. A probability level of $P<0.05$ was chosen as the limit for statistical significance in all tests, and probability levels of $P \leq 0.10$ were considered as a tendency.

\section{Results}

\subsection{Shooting accuracy}

The frequency of shots at the ideal position were low for both NPCB and PCB (Table 1), and the percentage of shots that deviated more than two centimeters radius from that position were also high for both methods (72.7 vs. $65.4 \%$, respectively).

The frequencies of shots according to gun type and shot entry position are shown in Fig. 1. The percentage of shots striking at the 
Table 1

Frequency of shots at the ideal shooting position in cattle heads and the deviation in $\mathrm{cm}$ from that position, when shot with pneumatically powered non-penetrating captive bolt gun (NPCB, 210-220 psi) and with pneumatic penetrating captive bolt gun (PCB, $190 \mathrm{psi}$ ).

\begin{tabular}{llll}
\hline $\begin{array}{l}\text { Shot deviation from ideal shooting } \\
\text { position } \\
(\mathrm{cm})\end{array}$ & $\begin{array}{l}\text { NPCB }(\mathrm{N}=88) \\
\text { (\% of shots) }\end{array}$ & $\begin{array}{l}\text { PCB }(\mathrm{N}=353) \\
(\% \text { of shots })\end{array}$ & $P$ \\
\hline Ideal shooting position & 5.7 & 3.1 & 0.333 \\
1 & 5.7 & 12.4 & 0.087 \\
2 & 15.9 & 19.2 & 0.542 \\
3 & 28.4 & 19.8 & 0.083 \\
4 & 14.8 & 18.1 & 0.532 \\
5 & 11.4 & 11.9 & 1.000 \\
6 & 8 & 8.8 & 1.000 \\
7 & 5.6 & 5.1 & 0.790 \\
8 & 4.5 & 1.4 & 0.082 \\
9 & 0 & 0.3 & 1.000 \\
\hline
\end{tabular}
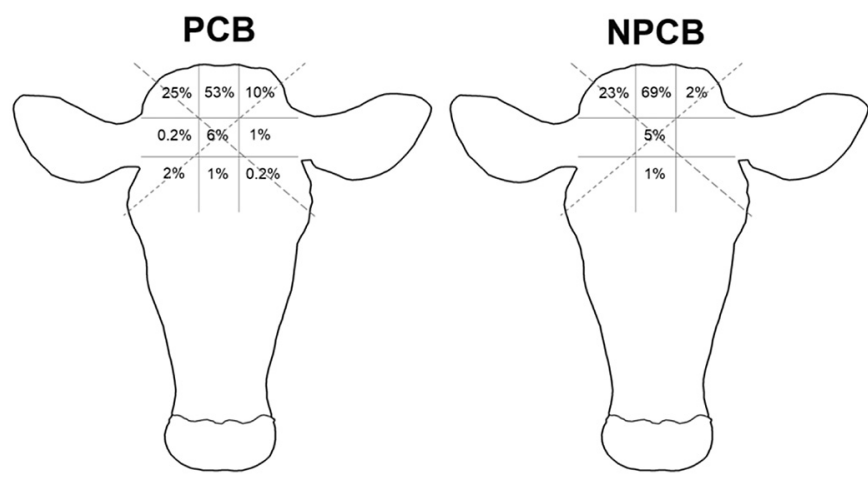

Fig. 1. Frequency of shot entry position according to the orientation on the head and gun type. PCB: penetrative captive bolt; NPCB: non-penetrative captive bolt. Intersection of dashed lines represent the ideal position.

predefined target region (up to two $\mathrm{cm}$ from the ideal position) were low for both methods ( $6 \%$ vs. $5 \%$, for PCB and NPCB, respectively; Fig. 1). Accordingly, there was a higher frequency of shots hitting the head nearer the crown of the heads for both methods ( 88 vs. $94 \%$, for PCB and NPCB, respectively; Fig. 1).

\subsection{Clinical signs of brain function}

There was no significant association between shot entry position or distance from ideal position for any of the clinical signs of consciousness/unconsciousness for either treatment $(P=0.9)$. However, there was a significant difference $(P<0.001)$ between NPCB and PCB in the number of cattle that collapsed at the first shot $(91 \%$ vs. $99 \%$, respectively). The frequency of cattle that received two or more shots was significantly higher $(P<0.001)$ when shot with NPCB than PCB (Table 2). For NPCB, eight shots were necessary to make one bull collapse. Cattle shot with NPCB presented more physical signs indicative of incomplete stunning compared with $\mathrm{PCB}$. Just after the animal had rolled out of the stunning pen (GR), cattle shot with NPCB showed a higher occurrence of righting reflex $(7 \%$ vs. $1 \%, P<0.001)$ and full eyeball rotation $(5 \%$ vs. $1 \%, P<0.001)$ than PCB. Cattle shot with NPCB also presented less tongue protrusion ( $36 \%$ vs. $61 \%, P<0.001)$ and more responses to nostril stimulation $(2 \%$ vs. $0 \%, P=0.04)$ than PCB at BL (Table 2). With the exception of the frequency of 2 or more shots delivered in the stunning pen, the results for the clinical signs presented in Table 1 relate to the outcome from the first and only shot or the final shot given to each animal.

\subsection{Bolt physical parameters}

The values of mean peak bolt velocity, momentum, kinetic energy,
Table 2

Frequency of physical signs of brain function in cattle after being shot with pneumatic non-penetrating captive bolt gun (NPCB, 210-220 psi) and penetrating captive bolt gun (PCB, 190 psi) assessed on the ground, just after the animal had rolled out of the stunning pen (GR), just after being hoisted (HO), and at the bleeding rail (BL).

\begin{tabular}{|c|c|c|}
\hline Local of assessment and physical signals & $\begin{array}{l}\text { NPCB }(\mathrm{N}=92) \\
\text { (\% of occurrence) }\end{array}$ & $\begin{array}{l}\text { PCB }(\mathrm{N}=363) \\
(\% \text { of occurrence) }\end{array}$ \\
\hline \multicolumn{3}{|l|}{ Stunning pen } \\
\hline Two or more shots & $29^{\mathrm{a}}$ & $12^{\mathrm{b}}$ \\
\hline \multicolumn{3}{|l|}{ GR } \\
\hline Rhythmic respiration & $12^{\mathrm{a}}$ & $8^{\mathrm{a}}$ \\
\hline Righting behaviour & $7^{\mathrm{a}}$ & $1^{\mathrm{b}}$ \\
\hline Tremor & $29^{\mathrm{a}}$ & $28^{\mathrm{a}}$ \\
\hline Masseter relaxation & $46^{\mathrm{a}}$ & $48^{\mathrm{a}}$ \\
\hline Tongue protrusion & $13^{\mathrm{a}}$ & $12^{\mathrm{a}}$ \\
\hline Responding to nostril stimulation & $2^{\mathrm{a}}$ & $3^{\mathrm{a}}$ \\
\hline Palpebral reflex - Corneal reflex & $2^{\mathrm{a}}$ & $1^{\mathrm{a}}$ \\
\hline Eyeball rotation & $5^{\mathrm{a}}$ & $1^{\mathrm{b}}$ \\
\hline Tonic convulsion & $64^{\mathrm{a}}$ & $62^{\mathrm{a}}$ \\
\hline Clonic convulsion (score 1 ) & $12^{\mathrm{a}}$ & $20^{\mathrm{a}}$ \\
\hline Clonic convulsion (score 2 or 3 ) & $18^{\mathrm{a}}$ & $14^{\mathrm{a}}$ \\
\hline \multicolumn{3}{|l|}{$\mathrm{HO}$} \\
\hline Rhythmic respiration & $3^{\mathrm{a}}$ & $1^{\mathrm{a}}$ \\
\hline Righting behaviour & $18^{\mathrm{a}}$ & $16^{\mathrm{a}}$ \\
\hline Tremor & $1^{\mathrm{b}}$ & $6^{\mathrm{a}}$ \\
\hline Tongue protrusion & $47^{\mathrm{a}}$ & $46^{\mathrm{a}}$ \\
\hline Blood extravasation & $12^{\mathrm{b}}$ & $22^{\mathrm{a}}$ \\
\hline Tonic convulsion & $0^{\mathrm{a}}$ & $0.3^{\mathrm{a}}$ \\
\hline Clonic convulsion (score 1 ) & $26^{\mathrm{a}}$ & $34^{\mathrm{a}}$ \\
\hline Clonic convulsion (score 2 or 3 ) & $30^{\mathrm{a}}$ & $25^{\mathrm{a}}$ \\
\hline \multicolumn{3}{|l|}{ BL } \\
\hline Rhythmic respiration & $4^{\mathrm{a}}$ & $2^{\mathrm{a}}$ \\
\hline Righting behaviour & $1^{\mathrm{a}}$ & $3^{\mathrm{a}}$ \\
\hline Tremor & $2^{\mathrm{a}}$ & $4^{\mathrm{a}}$ \\
\hline Tongue protrusion & $36^{\mathrm{b}}$ & $61^{\mathrm{a}}$ \\
\hline Responding to nostril stimulation & $2^{\mathrm{a}}$ & $0^{\mathrm{b}}$ \\
\hline Clonic convulsion (score 1 ) & $9^{\mathrm{a}}$ & $9^{\mathrm{a}}$ \\
\hline Clonic convulsion (score 2 or 3 ) & $1^{\mathrm{a}}$ & $6^{\mathrm{a}}$ \\
\hline
\end{tabular}

Frequency in a row without a common superscript letter were significantly different $(P<0.05)$.

energy density and sectional density were all significantly higher $(P<0.001)$ for PCB than NPCB (Table 3). Fig. 2 shows the mean velocity profiles of the captive bolt guns for the two stunning methods. The measurements for bolt velocity along the velocity meter showed a significant variation in velocity profile and peak velocity between the captive bolt gun types. Peak velocity occurred when the bolt transected the fourth infrared LED, which was positioned $16 \mathrm{~mm}$ from the top of the velocity meter. The distance from the recessed bolt to this sensor was $104 \mathrm{~mm}$. After this point, the velocity of NPCB steadily decreased to almost zero, whereas the PCB ended with a mean velocity of $35.9 \mathrm{~m} * \mathrm{~s}^{-1}$. At $96 \mathrm{~mm}$ of bolt travel, muzzle velocity represents the impact moment of the bolt against the animals' head when using the PCB (Fig. 2), and the mean velocity of the captive bolt for PCB gun was $31.1 \pm 0.5 \mathrm{~m} * \mathrm{~s}^{-1}$ (144 joules of kinetic energy), compared to $13.4 \pm 0.2 \mathrm{~m} * \mathrm{~s}^{-1}$ (74 joules of kinetic energy) for the NPCB gun.

\section{Discussion}

One often reported sign of effective stunning and loss of consciousness is the collapse of the animal immediately after the first shot (Terlouw, Bourguet, \& Deiss, 2016). When shooting with NPCB with the appropriate power load, the impact of the blunt bolt with the skull at the frontal position of the head has been suggested to be sufficient to induce concussion of the brain and consequently unconsciousness (EFSA, 2013). Thus, effectively shot cattle should collapse immediately after the impact of the bolt, which may result from damage to the reticular formation that plays a role in maintaining posture (Laureys \& Tononi, 2009). In this study, however, a higher proportion of cattle 
Table 3

Mean values ( \pm SE) of recorded bolt velocity and calculated values of momentum, kinetic energy, energy density and sectional density according to the stunning method.

\begin{tabular}{|c|c|c|c|c|c|c|c|}
\hline Stunning method & Number of shots & $\begin{array}{l}\text { Bolt weight } \\
(\mathrm{kg})\end{array}$ & $\begin{array}{l}\text { Mean peak bolt velocity } \\
\pm \mathrm{SE}(\mathrm{m} / \mathrm{s})\end{array}$ & $\begin{array}{l}\text { Momentum } \\
\pm \mathrm{SE} \text { (Ns) }\end{array}$ & $\begin{array}{l}\text { Kinetic energy } \\
\pm \text { SE }(J)\end{array}$ & $\begin{array}{l}\text { Energy density } \\
\pm \mathrm{SE}\left(\mathrm{J} / \mathrm{mm}^{2}\right)\end{array}$ & $\begin{array}{l}\text { Sectional density } \\
\left(\mathrm{wt} / \operatorname{diam}^{2}\right)\end{array}$ \\
\hline NPCB (220 psi) & 10 & 0.83 & $18.06^{\mathrm{b}} \pm 0.19$ & $14.90^{\mathrm{b}} \pm 0.16$ & $135.17^{\mathrm{b}} \pm 2.85$ & $0.14^{\mathrm{b}} \pm 0.01$ & 0.97 \\
\hline РСВ (190 psi) & 21 & 0.30 & $54.60^{\mathrm{a}} \pm 1.33$ & $16.20^{\mathrm{a}} \pm 0.39$ & $447.91^{\mathrm{a}} \pm 22.02$ & $2.30^{\mathrm{a}} \pm 0.11$ & 1.64 \\
\hline
\end{tabular}

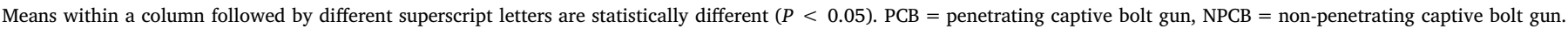

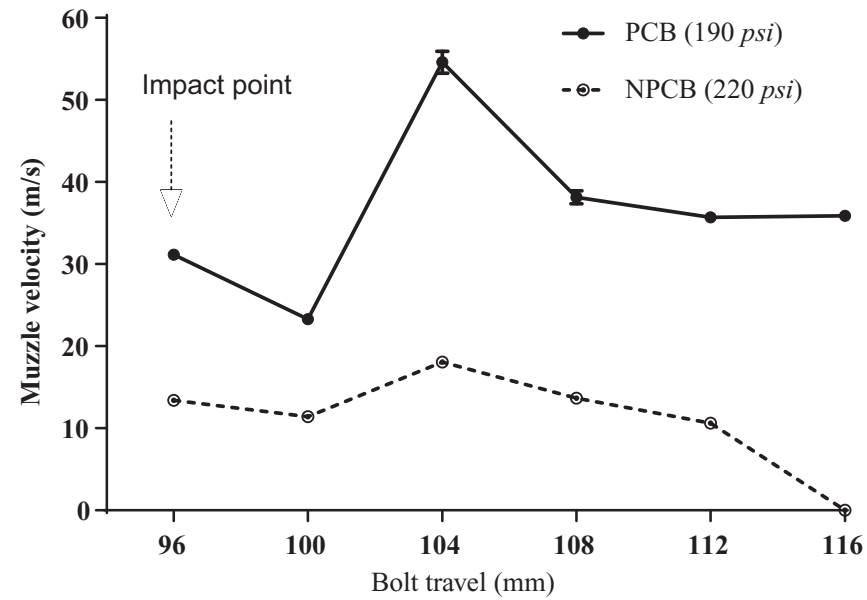

Fig. 2. Profiles of muzzle velocity for penetrative captive bolt (PCB) and non-penetrative captive bolt (NPCB) guns.

failed to collapse at the first shot when shot with NPCB compared with the PCB ( 9 vs. $1 \%, P=0.0002$ ). For both failed and successful shots there was a high proportion that where shot outside of the ideal position, high on the head (towards the crown). However, there was no significant association between shot entry position or distance from ideal position for any of the clinical signs of consciousness/unconsciousness for either treatment.

Cattle shot with NPCB showed a higher occurrence of righting behaviour when compared to PCB (7 vs. $1 \%, P<0.001$ ), which, according to Anil (1991), indicates the return to a conscious state. In this study, righting behaviour was identified by the vertical movement of the head and neck, associated with its attempts to return to standing posture. Thus, an animal on the floor that is conscious following an unsuccessful stun may attempt to lift the head and/or body, or at least to position them in the usual angle. After an effective stun, as long as the animal is unconscious, it does not attempt to recover its normal posture (Terlouw et al., 2016).

In this study, a higher occurrence of full eyeball rotation was observed at GR when cattle were shot with NPCB than PCB ( $5 \%$ vs. $1 \%$, $P<0.001$ ). Partial or full eyeball rotation are signs that have been used previously to indicate a shallower depth of unconsciousness and a return of consciousness, respectively (Atkinson, Velarde, \& Algers, 2013; Gregory et al., 2007). However, it is important to consider the degree of the eyeball rotation, since one study showed that the presence of a full rotation required a second stun, while a partial rotation required increased monitoring of other clinical signs of consciousness (Atkinson et al., 2013).

The frequency of tongue protrusion when cattle were hung on the bleed rail was higher when using PCB ( 61 vs. $36 \%, P<0.001)$ than NPCB. Unconscious animals will show general loss of muscle tone, which can be recognised from the relaxed jaws with protruding tongue (EFSA, 2013). There is no consensus in the literature whether or not tongue protrusion is a useful indicator of depth of concussion. If the tongue is fully extended, limp, and flaccid, it indicates the jaw muscles are relaxed and suggests the animal is properly stunned and insensible (Grandin, 2002; Gregory et al., 2007). On the other hand, its absence is only meaningful in terms of likely consciousness if the jaw muscles are also shown to be tense (Gregory et al., 2007).

A higher occurrence of cattle responding to nostril stimulation at the bleeding rail was found when cattle were shot with NPCB (2 vs. $0 \%$, $P<0.001$ ) than PCB, indicating a potential risk of consciousness or incomplete concussion of these animals as revealed by this polysynaptic reflex that involves activation of nociceptors (Anil \& McKinstry, 1991; Erasmus, Turner, \& Widowski, 2010). Among other pain withdrawal reflexes, the response to nostril stimulation (elicited by a painful stimulus to the cattle's nostril after stunning and/or bleeding) was highly valued in a survey on expert opinion as an indicator to assess unconsciousness after all types of stunning (Gerritzen \& Hindle, 2009).

Mechanical stunning of animals for slaughter is achieved by using penetrating and non-penetrating captive bolt guns (Blackmore \& Delaney, 1988). Comparing the two methods, the opinion of the Scientific Panel on Animal Health and Welfare (EFSA, 2004) stated that penetrating captive bolt stunning has several animal welfare advantages over non-penetrating captive bolt stunning (such as success rate and duration of unconsciousness) and, if properly used, results in an effective stun. It is thought that to have a good effectiveness, nonpenetrating captive bolt stunning (percussive stunning) requires greater accuracy, control of recoil and contact of the gun with the head (Gibson et al., 2015; Gibson, Mason, Spence, Barker, \& Gregory, 2015). However, in this study there was no significant difference in the frequency of animals being shot at the ideal position with either NPCB or PCB. Moreover, for NPCB, eight shots were necessary to make one bull to collapse, and 31 animals had to be shot again even though they had already collapsed after the first shot.

Both methods (penetrating and non-penetrating) operate via the transference of kinetic energy from the bolt to the brain (Farouk, 2013). The result may be neuronal destruction caused by bolt penetration through the brain and/or neuronal dysfunction, achieved as a consequence of a sudden direct blow of a wider bolt to the head. Pneumatically powered captive bolt guns use compressed air as the source of energy when the gun is fired, which is converted into kinetic energy of the moving bolt. Although the PCB and NPCB were operating with proper air line pressures, that where above the minimum recommended by the manufacturers, the results of the study demonstrate the superior effectiveness of PCB compared to NPCB for stunning adult beef cattle, with fewer signs of incomplete concussion.

The likely explanation for cattle shot with PCB having fewer signs of imperfect stunning lies in the amount of kinetic energy transmitted by the bolt to the cattle's cranium. According to Hampton et al. (2016), the kinetic energy delivered is of critical importance when inducing instantaneous insensibility, and, as stated by Gibson, Mason, et al. (2015), the kinetic energy delivered to the head during stunning is affected to a much greater extent by variation in the velocity of the captive bolt as opposed to the mass of the bolt. In this study, the average kinetic energy delivered with the PCBs (448 joules) was significantly greater $(P<0.001)$ than that by the NPCBs $(135$ joules). This was less than that recommended by the HSA (1999), which states that the impact energy of at least 200 joules is necessary for an effective stun in adult cattle.

Since the heads of the shot cattle were immobilized with a head yoke and as long axes of the brain and spinal column are parallel (which may reduce rotational shearing after non-penetrating stunning), the 
injury transmitted to the brain may have been less than if it were free (Crooks, 1991). Since NPCB should cause fast angular acceleration of the head after the impact of the large bolt with the skull with acceleration/deceleration forces imparting large-momentum, rotational, and shear forces to the head and brain at relatively low kinetic energy (Ommaya et al., 2002), the values of momentum calculated for NPCB in this study (14.9 Ns) may have been insufficient. However, there are no studies evaluating the minimum requirements of momentum that leads to effective stun in livestock species.

Additionally, there may have been more physical damage to particular brain structures, such as the brainstem when shooting with PCB than with NPCB, since work by Oliveira (2017) found that direct damage to brainstem structures was achieved only when shooting with PCB (operating with 190 psi), while no macroscopic damage was found for NPCB. Moreover, fragmented bone resulting from the collision of the penetrating bolt with the cranium may have increased the transfer of energy to the brain, providing a large number of secondary fragments to produce widespread soft tissue disruption in the vicinity of the bone (Cooper \& Ryan, 1990).

\section{Conclusion}

In conclusion, $\mathrm{PCB}$ was more effective in reliably stunning adult cattle than NPCB. The results suggest that stunning with NPCB may increase the risk of cattle being incompletely stunned and suffering at slaughter. The findings confirm that PCB is an effective stunning method for slaughter of adult cattle. The authors hope these results will stimulate further research and lead to development, identification and use of technologies to improve welfare of animals at stunning.

\section{Acknowledgements}

This study was conducted as part $\mathrm{PhD}$ thesis of the lead author in the Animal Science Graduate Program at the Faculty of Agricultural and Veterinary Sciences, UNESP, Jaboticabal, SP, Brazil. The research was partially funded by CNPq (that granted the scholarships to Steffan Edward Octávio Oliveira and Filipe Antônio Dalla Costa) and by FAPESP (grant number 2016/24.910-4) for supporting Prof. Neville G. Gregory as a visiting professor at FCAV-UNESP, Jaboticabal campus. The authors also express the gratitude to Everton Adriano Andrade and Carlos Alberto de Oliveira Silva for their support during data collection, and to Karen Camille Góis, Maria Camila Ceballos, Monique Valéria de Lima Carvalhal for their contribution in data collection. This study would not be possible without the support of JBS, which opened its facilities for data collection. Thanks should be also given to Dr. Arlei Coldebella for his assistance with the data analysis.

\section{References}

Anil, M. H. (1991). Studies on the return of physical reflexes in pigs following electrical stunning. Meat Science, 30, 13-21.

Anil, M. H., \& McKinstry, J. L. (1991). Reflexes and loss of sensibility following head-toback electrical stunning in sheep. The Veterinary Record, 128, 106-107.

Atkinson, S., Velarde, A., \& Algers, B. (2013). Assessment of stun quality at commercial slaughter in cattle shot with captive bolt. Animal Welfare, 22, 473-481.

Blackmore, D. K., \& Delaney, M. W. (1988). Slaughter of stock (Publication no. 18) Palmerston North, New Zealand: Foundation for Continuing Education of The N.Z. Veterinary Association, Massey University.

Cooper, G. J., \& Ryan, J. M. (1990). Interaction of penetrating missiles with tissues: Some common misapprehensions and implications for wound management. British Journal of Surgery, 77, 606-610.

Crooks, D. A. (1991). The pathological concept of diffuse axonal injury; its pathogenesis and the assessment of severity. Journal of Pathology, 165, 5-10.

EFSA, European Food Safety Authority (2004). Welfare aspects of the main systems of stunning and killing the main commercial species of animals. The EFSA Journal, 45, $1-29$.

EFSA, European Food Safety Authority (2013). Scientific opinion on monitoring procedures at slaughterhouses for bovines. The EFSA Journal, 11(12), 1-65.

Erasmus, M. A., Turner, P. V., \& Widowski, T. M. (2010). Measures of insensibility used to determine effective stunning and killing of poultry. Journal of Applied Poultry Research, 19, 288-298.

Farouk, M. M. (2013). Advances in the industrial production of halal and kosher red meat. Meat Science, 95, 805-820.

Finnie, J. W. (2001). Animal models of traumatic brain injury: A review. Australian Veterinary Journal, 79, 628-633.

Finnie, J. W., Blumbergs, P. C., Manavis, J., Summersides, G. E., \& Davies, R. A. (2000). Evaluation of brain damage resulting from penetrating and non-penetrating captive bolt stunning using lambs. Australian Veterinary Journal, 78, 775-778.

Gerritzen, M. A., \& Hindle, V. A. (2009). Indicatoren voor bewusteloosheid. Wageningen UR Livestock Research. Retrieved November 1, 2013, (from) http://edepot.wur.nl/ 12436.

Gibson, T. J., Mason, C. W., Spence, J. Y., Barker, H., \& Gregory, N. G. (2015). Factors affecting penetrating captive bolt gun performance. Journal of Applied Animal Welfare Science, 18, 222-238.

Gibson, T. J., Whitehead, C., Taylor, R., Sykes, O., Chancellor, N. M., \& Limon, G. (2015). Pathophysiology of penetrating captive bolt stunning in alpacas (Vicugna pacos). Meat Science, 100, 227-231.

Grandin, T. (2002). Return-to-sensibility problems after penetrating captive bolt stunning of cattle in commercial beef slaughter plants. Journal of the American Veterinary Medical Association, 221, 1258-1261.

Gregory, N. G., Lee, C. J., \& Widdicombe, J. P. (2007). Depth of concussion in cattle shot by penetrating captive bolt. Meat Science, 77, 499-503.

Hampton, J. O., Adams, P. J., Forsyth, D. M., Cowled, B. D., Stuart, I. G., Hyndman, T. H., \& Collins, T. (2016). Improving animal welfare in wildlife shooting: The importance of projectile energy. Wildlife Society Bulletin, 40, 678-686.

HSA, Humane Slaughter Association (1999). Humane killing of livestock using firearms (Guidance notes n. 3, p. 11)Wheathampstead-UK: Humane Slaughter Association.

Laureys, S., \& Tononi, G. (2009). The neurology of consciousness: Cognitive neuroscience and neuropathology (1st ed.). London, UK: Academic Press.

Oliveira, S. E. O. (2017). Avaliação da eficiência da insensibilização de bovinos para o abate com uso de pistolas pneumáticas de dardo cativo. Universidade Estadual Paulista (UNESP) (PhD Thesis. 85p).

Oliveira, S. E. O., Gregory, N. G., Dalla Costa, F. A., Gibson, T. J., \& Paranhos da Costa, M. J. R. (2017). Efficiency of low versus high airline pressure in stunning cattle with a pneumatically powered penetrating captive bolt gun. Meat Science, 130, 64-68.

Ommaya, A. K., Goldsmith, W., \& Thibault, L. (2002). Biomechanics and neuropathology of adult and pediatric head injury. British Journal of Neurosurgery, 19, 843-853.

Summers, B. A., Cummings, J. F., \& de Lahunta, A. (1995). Veterinary neuropathology. St Louis, MO: Mosby, Elsevier.

Terlouw, C., Bourguet, C., \& Deiss, V. (2016). Consciousness, unconsciousness and death in the context of slaughter. Part II. Evaluation methods. Meat Science, 118, 147-156. 